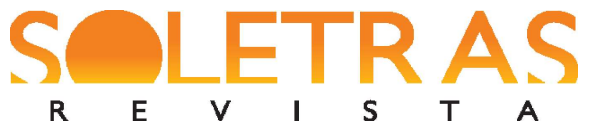

\section{Posição responsável na língua que ensino/aprendo: análise da relação do professor de inglês com as aulas (de inglês) em um curso de formação continuada}

\author{
Valdeni da Silva Reis ${ }^{1}$
}

\begin{abstract}
Resumo: O presente trabalho objetiva investigar os efeitos de sentido mobilizados por professores de língua inglesa (LI) participantes de um projeto de formação continuada, de uma universidade federal do estado de Minas Gerais. De modo mais específico, estaremos focados na análise de deslocamentos discursivos/subjetivos oriundos de sua participação em aulas de LI ministradas por duas americanas bolsistas Capes/Fulbright, em um dos módulos do projeto. Com apoio principalmente nos construtos teóricos em torno da responsabilização e do posicionamento discursivo/subjetivo, serão analisados relatos escritos pelos professores, no intuito de explorar o modo como eles significam essa experiência, (re)significando sua prática e seu modo de nela se posicionar como professor/a de língua inglesa. Resultados indicam que as aulas de LI oferecidas no projeto convocam o professor a um complexo processo de responsabilização e (re)posicionamento.
\end{abstract}

Palavras-chave: Educação continuada para professores de língua inglesa. Professores de língua inglesa. Responsabilização. Posição discursiva. Deslocamentos subjetivos/discursivos.

\title{
Introdução
}

Dentre os desafios vivenciados por professores de inglês no Brasil, sabemos que um dos mais importantes é que, muitas vezes, embora possuam um certificado que lhes garante o lugar de professor, eles lidam com a angústia de (ter de) ensinar uma língua que ainda lhes parece escapar. Nesse sentido, a educação continuada pode abrir, a seus participantes, possibilidades teórico-metodológicas e linguísticas que lhes possibilitem assumir definitivamente sua posição de professor de língua inglesa (LI).

Interessamo-nos, assim, pelo modo como o sujeito ocupa seu lugar de professor, responsabilizando-se aí por sua posição discursiva e, consequentemente, por sua formação e prática. O presente trabalho objetiva investigar os efeitos de sentido mobilizados por professores de língua inglesa participantes de um projeto de formação continuada, de uma universidade federal do estado de Minas Gerais. De modo mais específico, estaremos focados nos deslocamentos discursivos oriundos de sua participação em aulas de LI ministradas por duas americanas bolsistas Capes/Fulbright, em um dos módulos do projeto.

\footnotetext{
${ }^{1}$ Professora Adjunta (Linguística Aplicada - Inglês) da Faculdade de Letras da Universidade Federal de Minas Gerais e do Programa de Pós-Graduação em Estudos Linguísticos (POSLIN). Doutora em Linguística Aplicada também pela UFMG. MG, Brasil. E-mail: valdeni.reis@gmail.com.
} 
Com apoio principalmente nos construtos teóricos em torno da responsabilização e da posição discursiva, serão analisados enunciados de professores, no intuito de explorar o modo como eles significam essa experiência, (re)significando sua prática e seu modo de nela se posicionar como professor/a de LI.

A seguir, discutiremos brevemente alguns pontos referentes à educação continuada de professores de língua estrangeira (LE) no Brasil, além de apresentarmos alguns conceitos importantes para nossa investigação. Posteriormente, discorreremos sobre contexto e participantes do estudo, bem como a metodologia de coleta e análise de dados. Por fim, discutiremos algumas implicações do estudo, seguidas das considerações finais da presente proposta.

\section{Ensino-Aprendizagem da LI: Desejo, Necessidade, Formação}

O ensino-aprendizagem de uma língua estrangeira porta consigo algo relacionado a atração, paixão, captura ou, até mesmo, a necessidade. De um modo ou de outro, o fortuito contato com o som ou com a grafia de uma LE pode ser a mola propulsora para que o sujeito deseje aprendê-la. Não raras vezes, uma música, uma banda, um jogo atraem o sujeito para uma determinada língua de modo irremediável. Do mesmo modo, em momentos que a comunicação humana entre diferentes povos se torna imprescindível, saber uma LE passa a ser uma questão vital.

Paiva (2003) salienta que, na história da humanidade, sempre houve interesse pelas línguas estrangeiras. Desse modo, por motivos bélicos ou pacíficos, as civilizações antigas sempre buscaram aprender outros idiomas (PAIVA, 2003). Vemos, então, com a autora, que as línguas estrangeiras servem, desde sempre, como mediadoras nas complexas relações e desenvolvimento humano, no que se refere à política, ao comércio, ao conhecimento científico, à produção cultural etc.

Há algumas décadas, a língua inglesa é considerada a língua mais importante do mundo, sendo a língua da divulgação do conhecimento científico, tecnológico; a língua da internet; a língua do comércio e do consumo de bens, serviços, cultura. Nas palavras de Rajagopalan (2005, p. 135), "a língua inglesa se encontra profundamente estabelecida como a língua-padrão do mundo como parte intrínseca da revolução global das comunicações”. 


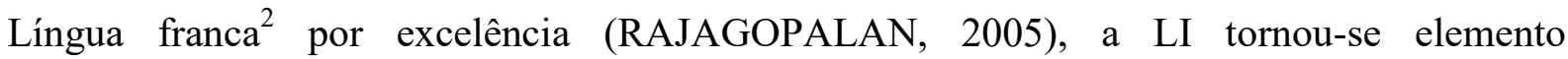
indispensável em tempos de globalização e desterritorialização (RAJAGOPALAN, 2003; 2005).

Essa língua, inegavelmente importante para todo o mundo, no que se refere à produção e distribuição de conhecimento, tem seu ensino intensificado no Brasil após a Segunda Guerra Mundial (LEFFA, 1999; PAIVA, 2003). Segundo os autores, esse evento instaura, além de maior imigração de falantes da língua inglesa para o Brasil, o aumento da dependência econômica e cultural brasileira em relação aos Estados Unidos, criando-se, concomitantemente, a necessidade e/ou desejo cada vez maior de se aprender a língua inglesa.

Podemos então dizer que, dada sua importância mundial, a LI conquistou, ao longo dos tempos, obrigatoriedade nos currículos das escolas públicas brasileiras. O que não podemos afirmar, contudo, é que nossas políticas educacionais tenham conseguido acompanhar esse movimento, de modo a assegurar reconhecida qualidade para o ensino de LI em nossas escolas regulares.

Deste modo, a despeito de todo o discurso acerca da importância da LI para o mundo globalizado e os decorrentes desafios a serem encarados por nossos alunos - futuros profissionais e cidadãos deste mundo -, não podemos dizer que seu ensino e aprendizagem sejam indiscutivelmente valorizados ou eficazes em nossa educação. Com isso, entendemos que, apesar da crescente e necessária discussão em torno da existência de práticas bem sucedidas na sala de aula de LI no ensino regular (CUNHA; MICCOLI, 2016; ARRUDA, 2014; COELHO, 2011; entre outros), na grande maioria de nossas escolas, o inglês é ainda rotulado como ineficiente, desinteressante e repetitivo (BATISTA; PORTO, 2005; REIS, 2018, entre outros). É comum, portanto, a imagem de que, na escola regular, não se ensina/aprende a LI de fato.

Outros motivos que também reforçam o discurso do fracasso do ensino de inglês estão relacionados às precárias condições das salas de aula da maioria das escolas brasileiras, tais como a carga horária reduzida, a carência de material didático, sendo este reduzido ao giz e ao livro didático, as classes superlotadas, indisciplina (ARRUDA, 2014; ZOLNIER, 2007; DUTRA; OLIVEIRA, 2006; BATISTA; PORTO, 2005; entre outros). A ineficiência do

\footnotetext{
${ }^{2}$ Segundo Seidlhofer (2011, p. 7), o uso da língua inglesa como língua franca significa "qualquer uso do inglês entre falantes de diferentes línguas maternas", que o elegem como meio de comunicação por preferência ou por necessidade.
} 
ensino-aprendizagem de LI é também atribuída ao pouco domínio das habilidades orais por parte de muitos professores (ALMEIDA FILHO, 1992), o que é ainda mais complexo e ponto central para a presente discussão.

Para Costa (1987), a mediação do professor é fundamental, em todo o percurso de aprendizagem, que abrange ainda o desenvolvimento e o aprimoramento de atitudes do aprendiz, em relação ao objeto ou elemento aprendido. Desse modo, os conhecimentos do professor acerca daquilo que ele ensina (a língua que ele deve ensinar) e do modo como deve ser ensinado (o que é da ordem de sua prática) constituem elementos essenciais para promover descobertas e reflexão sobre essas descobertas. Esse movimento é fundamental para despertar a curiosidade e investimento do aluno em sua aprendizagem, aqui compreendidos como elementares para sua trajetória acadêmica e pessoal.

Acreditamos, assim, que o maior desafio que o professor de LI pode enfrentar, em nossa realidade brasileira, é o fato de possuir um diploma que legitima sua prática, tendo, no entanto, a consciência de suas limitações linguísticas. Segundo Almeida Filho (2001), não raras vezes, "o professor não fala, pouco lê, não escreve e nem entende a LE de sua habilitação, quando em uso comunicativo". Resta-lhe, portanto, prossegue o autor, estudar pontos fragmentados e simplificados da língua, de modo a transmiti-los a seus alunos.

Não obstante o fato de que nossas instituições de ensino devem ser capazes de garantir que o professor, ao se formar, tenha condições de exercer as funções que lhe sejam confiadas, incluindo aí seu desempenho linguístico, defendemos que a formação do professor de LE não está finalizada com a aquisição de um diploma. Em outras palavras, entendemos que a formação do professor transcende os limites espaço-temporais de nossos cursos de formação (REIS, 2016) inicial. Nesse sentido, os programas/projetos de educação continuada (EC) são extremamente relevantes para o aprimoramento dos professores.

A EC é aqui compreendida como um conjunto de ações em que o professor em exercício se implique, numa relação que o convoque ao trabalho norteado pelos formadores, numa proposta planejada, mas também dinâmica, de possíveis movimentos e (re)posicionamento discursivo, social e profissional. A EC se constitui de iniciativas oferecidas ao professor em serviço, geralmente - mas não restritamente - por instituições de ensino superior, ligando universidade e escolas regulares.

Segundo Bohn (2000), a EC funciona como uma espécie de atualização e, de modo especial, como um espaço no qual os professores podem partilhar experiências e 
conhecimentos, que serão levados para suas salas de aula. Freeman (1996) defende que é importante considerar que a experiência é a referência mais palpável que cada professor carrega consigo, e pode ser partilhada na elaboração de novos conceitos. O que o professor experimenta, portanto, em um curso de EC pode se revelar como fator primordial para que o professor consiga se posicionar como tal, (re)descobrindo caminhos profícuos (e responsáveis) para seu fazer.

\section{Lugar e posição responsável no ensino-aprendizagem da LI}

$\mathrm{Na}$ grande maioria das vezes, os professores de LI vão em busca da EC visando, mais que atualização ou aprofundamento didático-pedagógico, seu desenvolvimento linguístico, a fim de ficar mais próximo e íntimo da língua que ensina. Em um curso de formação de EC, o professor pode ter a oportunidade de descobrir-se na posição de responsabilização e, assim, ser impelido a assumir sua posição de professor de LI em todas as suas implicações. Nas palavras de Reis (2011, p. 505), defendemos que,

na posição de responsabilização, o sujeito-professor questiona sua prática, buscando compreender aquilo que não dá certo, sua solidão, suas angústias. Muitas vezes, é esse o principal sentimento que leva um professor a um projeto de educação continuada.

O filósofo alemão Hans Jonas ([1979], 2006) nos propõe uma instigante articulação entre os termos ética e responsabilização. Para o autor, ética está relacionada ao agir. Assim sendo, a ética a ser construída e trabalhada não se pauta em modelos de conduta, mas, antes, refere-se ao agir no risco e ao responsabilizar-se por tais ações. Nessa perspectiva, é possível compreender que é a magnitude dos impactos das ações do sujeito no mundo (nem sempre instantâneos ou imediatos) e sua possível irreversibilidade que deslocam "a responsabilidade para o centro da ética, considerando-se aí os horizontes espaço-temporais que correspondam àqueles atos" (JONAS [1979] 2006, p. 22). A ética do sujeito ao suportar seu corpo em ação, correndo riscos, sustentando consequências, responsabilizando-se.

Jonas (2006) defende que é possível ao sujeito assumir a responsabilidade não só por si próprio e por seus atos, mas, sobretudo, pelo objeto da certeza convencida que o move. Tal certeza faz que seja possível tolerar a angústia e assumir o risco de integrar em sua ação a 
convicção de que o inesperado e o imprevisível são indissociáveis das ações e relações estabelecidas entre os sujeitos.

Para o presente trabalho, o termo responsabilização será discutido a partir do modo como o sujeito (em EC) se descobre em sua posição discursiva, enunciando e se responsabilizando por seu lugar-posição (ORLANDI, 1999a; 1999b) de professor de língua inglesa. Interessamo-nos, pois, pelo modo como o sujeito se posiciona discursivamente, entendendo que isto é revelador do modo como ele aí se constitui.

Partindo de Orlandi (1999a), compreendemos que lugar é uma instância social e passível de descrição. Há, deste modo, o lugar de professor, conferido a partir de uma formação acadêmica, por exemplo. Já posição, por outro lado, se refere à tomada da palavra a partir do lugar social do sujeito, para negociar tanto efeitos de sentido, quanto posições discursivas. O sujeito assume, enfim, seu lugar, na medida em que fala, e aí se constitui em sua posição discursiva; isto é, constitui seu existir, ao falar e agir tal qual sócio historicamente demandado, de sua posição de professor de inglês, por exemplo.

Assim, entendemos o sujeito como posição que se delineia na medida em que, ao tomar a palavra, "se projeta de sua situação (lugar) no mundo para sua posição no discurso" (ORLANDI, 1999b, p. 17). Sua posição ou seu posicionamento responsável é construído, portanto, a partir do movimento em que o sujeito se descobre responsável por seu lugar social, permitindo-se assumir e sustentar tal posição discursivamente.

Investigaremos, finalmente, a participação do professor em EC, em um módulo de ensino-aprendizagem de inglês ofertado por duas norte-americanas, bolsistas Fulbright. De modo mais específico, estaremos centrados no modo como o sujeito-professor se constitui nesse processo, ocupando seu lugar de professor, mas, sobretudo, responsabilizando-se aí por sua posição discursiva e pelas decorrentes implicações em seu fazer pedagógico.

\section{Contexto e participantes}

O presente estudo analisa o modo como professores significam a experiência de aprendizagem de LI no projeto de EC Continuação Colaborativa $\left(\mathrm{Concol}^{3}\right)$, (re)significando

\footnotetext{
${ }^{3}$ Parte do Programa Interfaces da Formação em Línguas Estrangeiras da Faculdade de Letras da UFMG, que agrega três projetos, a saber, Educação Continuada de Professores de Línguas Estrangeiras (EDUCONLE), Continuação Colaborativa (ConCol) e UNISALE Parceria Universidade-Escola. O ConCol, foco do presente
} 
sua prática e seu modo de aí se inscreverem. As aulas de inglês foram desenvolvidas em um dos módulos do ConCol, ao longo de todo o ano letivo.

O projeto Continuação Colaborativa (ConCol) nasceu em 2011, no Programa Interfaces da Formação em Línguas Estrangeiras, da Faculdade de Letras/UFMG, visando promover a educação continuada de professores de LI de ensino básico, da rede pública do estado de Minas Gerais. O projeto nasce a partir da coleta de dados para a tese de doutorado da professora Vanderlice dos Santos Andrade Sól, que, ao entrar em contato com os egressos do projeto Educação Continuada de Professores de Línguas Estrangeiras (EDUCONLE), descobriu que havia uma urgente demanda, por parte desses alunos, de retomar seus estudos continuados (SÓL, 2014). A autora do presente estudo colaborou com projeto desde a sua criação, e atuava como subcoordenadora ${ }^{4}$ do mesmo, no ano de geração dos dados.

Ao longo de todo o período em que ocorreu a geração de dados aqui analisados, os alunos participaram sistematicamente dos módulos do projeto, sendo esses: 1. encontros quinzenais do grupo de discussões, nos quais os professores partilhavam experiência didáticopedagógicas ou leituras teórico-metodológicas; 2. Encontros semanais para desenvolvimento de oficinas e projetos de letramento digital; e 3. Aulas semanais de língua inglesa ministradas por duas bolsistas norte-americanas.

Dez professores em EC aceitaram colaborar com o presente estudo. Com idade entre 36 e 63 anos, todos são professores bem experientes, tendo de 14 a mais de 30 anos de profissão, no momento da realização do estudo. Duas participantes já estavam aposentadas, mas continuavam atuantes como professoras de LI. Os professores atuam, em sua maioria, em escolas estaduais e municipais do estado de Minas Gerais, mas as duas professoras aposentadas atuam como professoras particulares ou como voluntárias.

O curso EC contou com a colaboração de duas bolsistas English Teaching Assistants ETA - Capes-Fulbright, que ministraram as aulas de inglês no ano de realização do estudo. $\mathrm{O}$ programa ETA-Fulbright seleciona americanos recém-formados, com algum conhecimento em língua portuguesa, para atuar em universidades brasileiras parceiras no projeto. $\mathrm{O}$ programa estabelece, assim, que sejam atribuídas a seus bolsistas tarefas com objetivo de

estudo, é atualmente coordenado pela Professora Dra. Maralice de Souza Neves. Para maiores informações sobre o programa e seus projetos ver: http://www.letras.ufmg.br/interfaces/.

4 Vale ressaltar que atualmente a autora coordena o projeto UNISALE Parceria Universidade-Escola, que também compõe o Programa Interfaces da Formação em Línguas Estrangeiras. 
desenvolver a proficiência dos alunos de inglês nas universidades federais brasileiras, mas com um enfoque em elementos que promovam a cultura geral dos EUA. As duas bolsistas tinham 22 e 27 anos de idade, no ano em que participaram do projeto. Não trazemos para a presente discussão nenhum dado gerado a partir das duas bolsistas. Sua participação está aqui limitada a sua presença no discurso dos professores-alunos sobre as aulas por elas ministradas.

Durante as análises, utilizaremos nomes fictícios para os participantes do estudo. Também optamos por não divulgar o ano da realização da coleta de dados, como outra forma de preservar a identidade de seus participantes.

\section{Metodologia: constituição do corpus e marcas discursivas}

A presente análise segue o dispositivo de escuta discursiva (ORLANDI, 1999a), por meio da qual procuramos descrever e interpretar os efeitos de sentido mobilizados por professores em EC, a partir de sua participação nas aulas de inglês desenvolvidas no ConCol durante o ano de coleta.

O corpus é formado por relatos escritos por professores participantes do projeto, no ano em que a coleta foi realizada. Durante um dos encontros do projeto, os professores foram convidados a discorrer sobre o seguinte ponto: Como é estudar inglês dentro do ConCol: (o que isso significa para você?; o que isso significa para sua prática pedagógica/fazer profissional?).

Após receber os relatos, digitamos todo o material e fizemos um processo de análise preliminar e codificação dos enunciados, focando nossa atenção naqueles que traziam à tona recorrências que apontavam para alguns sentidos predominantes, tais como as aulas de inglês como algo enriquecedor, por exemplo.

O presente estudo é de cunho qualitativo, segundo a natureza de seus dados e nos valemos dos princípios e procedimentos da análise de discurso (ORLANDI, 1999a), para geração, tratamento e análise do corpus linguístico. O corpus é, desse modo, analisado com base nas ressonâncias discursivas (SERRANI-INFANTE, 2001), observando, deste modo, o que é recorrente no discurso. Segundo a autora, as ressonâncias discursivas se constituem a partir da repetição de certas marcas linguístico-discursivas, que trabalham na construção de um determinado significado predominante. Logo, a análise aqui empreendida é pautada no conteúdo dos enunciados e nos modos de enunciar que os constituem. Em outras palavras,

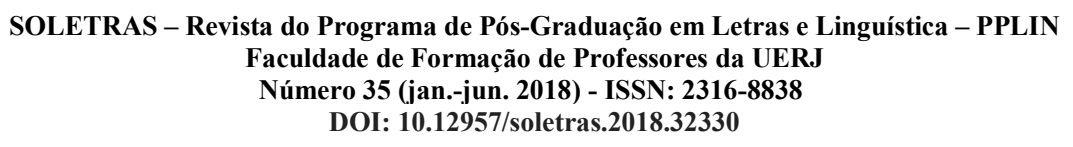


investigamos o modo como os efeitos de sentido são produzidos, mobilizados e como ressoam para a significação das aulas de inglês no projeto.

Serrani-Infante (2001, p. 40) propõe apenas três categorias de repetições, a saber: a) itens lexicais de uma mesma família de palavras, ou itens de diferentes raízes lexicais apresentados no discurso como semanticamente equivalentes; b) construções que funcionam parafrasticamente; c) modos de enunciar presentes no discurso (tais como o modo determinado e o modo indeterminado de enunciar; o modo de definir por negações, ou por afirmações modalizadas ou categóricas, modo de acréscimos contingentes através das incisas, glosas etc.). Porém, a partir de Reis (2006; 2007), utilizamos uma subcategoria, no intuito de facilitar a operacionalização das categorias. Assim, o conjunto de categorias das ressonâncias discursivas é o seguinte (quatro categorias e três subcategorias):

1. repetição de itens lexicais de uma mesma família de palavras;

2. repetição de itens de diferentes raízes lexicais, apresentados no discurso como semanticamente equivalentes;

3. repetição de construções que funcionam parafrasticamente;

4. modos de enunciar presentes no discurso:

4.1. modo determinado e modo indeterminado de enunciar;

4.2. modo de definir por negações ou afirmações modalizadas ou categóricas;

4.3. modo de acréscimos contingentes por meio de incisas e de glosas.

A guisa de esclarecimentos, podemos, por exemplo, discutir o uso recorrente feito pelo enunciador da palavra 'enriquecer' ou palavras dessa mesma família, tais como, 'enriquecedora' ou 'enriquecimento'. Palavras tais como 'melhoria/melhorar' e 'desenvolvimento/desenvolver' também podem ser consideradas equivalentes para a formulação de um sentido predominante (categoria de número 2). Ainda, o analista de discurso deve também ficar atento a formulações que utilizam estruturas e palavras diferentes, mas que podem fazer ressoar sentidos equivalentes, como que parafraseados.

Por fim, é necessário investigar o modo de dizer ou significar é formulado no discurso. Isto é, importa-nos o modo como os sentidos são mobilizados, na medida em que participante enuncia de forma direta, indireta, em primeira pessoa, de forma modalizada ou categórica, entre outros. O uso de uma glosa adversativa por meio das conjunções adversativas "mas" ou porém, por exemplo, pode redirecionar os efeitos de sentidos mobilizados no discurso. 


\section{Análise: aprendo a língua que ensino a língua que aprendo}

Os dizeres em relação à aula de língua inglesa do projeto nos indicam que esse módulo ocupa o espaço central, pois é capaz de fazer que a prática do professor seja mobilizada. Ao mesmo tempo, a relação desse professor com a língua que ele ensina é também mobilizada, desestabilizando certezas, reconstruindo/deslocando realidades. Transitar entre as posições de aluno e professor é revelador de realidades até então desconhecidas por este professor.

A palavra realidade e outras dessa mesma família circulam na constituição de um dizer predominante. Nesse sentido, vejamos o excerto abaixo:

[1]

Estudar inglês no CONCOL significa enriquecer a prática pedagógica e profissional, pois aqui é um 'laboratório real', onde as 'falhas', as 'limitações' dos professores são resolvidas de forma realista. Esse laboratório proporciona uma conscientização, em pormenores, que incita constantemente a reflexões que realmente validam nossa prática na vida real: que é lidar com a realidade do ensino de inglês em nossas escolas. (CARLOS) (negrito nosso)

Como visto no excerto 1, e também nos excertos que se seguirão, os dizeres sobre a aula de LI no projeto fazem ressoar tal experiência como oportunidade enriquecedora, capaz de conferir segurança ao professor e promover deslocamentos em sua realidade, de modo leve e envolvente. De algum modo, há a possibilidade de colorir tal realidade - outrora de brilho ofuscado, talvez pelo 'não-saber' [a língua que ensino] -, que ganha vida, como uma atividade de diversão da hora do recreio, ou em um parque.

Vejamos os excertos abaixo:

[2]

O estudo LE dentro do CONCOL TEM SIDO MUITO enriquecedor. [...] Por ser uma aula diversificada, acredito que está me auxiliando muito no meu cotidiano escolar. Sinto-me como se estivesse pela primeira vez em um playground. Toda aula é uma novidade, tem um assunto interessante para ser discutido. (MARCELA) (negrito nosso caixa alta da professora)

[3]

Muito enriquecimento intelectual, trazendo junto a oportunidade de aprimorar a Língua Inglesa dentro das suas quatro habilidades. (BERENICE) (negrito nosso)

Primeiramente é uma realização pessoal viver nesse ambiente acadêmico único, por si só já é enriquecedor. Me sinto orgulhoso em dizer que faço parte do CONCOL e em ter um amparo técnico nas minhas atividades. Quanto ao aprendizado da língua, é de suma importância o contato periódico. Acredito que ensinar é um aprendizado constante 
e que deve ser exercido com qualidade, qualidade que encontramos aqui. (FERNANDO) (negrito nosso)

A imagem do playground é frutífera. Ao ligar essa experiência a uma primeira vez em um playground, temos a imagem da descoberta infantil; da atração pelo diferente, colorido e novo, mas também o medo do terreno desconhecido. Curioso é assumirmos aqui que essa alusão ao novo, atração e medo, direcionada à experiência de aprendizagem de LE, ressoa da fala de professores já experientes dessa língua, mas que ainda a têm como estranha (CORACINI, 2003; REIS, 2012); ou como aquela que lhe causa estranhamentos.

Assim, a aprendizagem de LI dentro do projeto se dá de forma dinâmica, mas, como num playground, pode trazer consigo tanto algo que é da ordem da atração, quanto algo que é da ordem do medo. Conforme vemos em Coracini (2003, p. 149), o medo pode representar, na aprendizagem, "o medo do estranho, do desconhecido, o medo do deslocamento ou das mudanças que poderão advir da aprendizagem de uma outra língua”. Assim, medo e atração são pertencentes à mesma experiência, de (re)encontro com a LI, mas arriscando-se; entrar no playground, para brincar, com o risco de se machucar, é pagar para ver, é se arriscar nesse processo; é responsabilizar-se.

Abrir-se ao novo, com todos os seus estranhamentos e desafios, significa assumir o risco ou a dor de ver suas realidades mexidas, deslocadas. Entendemos que suportar tal experiência e suas consequências é assumir uma posição de responsabilidade.

Os dizeres em torno da aula de língua inglesa dentro do projeto nos indicam que, antes de qualquer outro aprendizado, o professor precisa aprender a lidar com suas próprias dificuldades, problemas e limitações. Ele precisa se ver responsável por ensinar uma língua, mesmo que não se sinta (ainda) devidamente preparado para tal. Posicionar-se a partir desse lugar não é simples, sem conflitos ou dores; suportar esse não-saber pode ser o primeiro passo para que seu fazer seja mobilizado, deslocando suas limitações e a forma de se constituir como professor de LI, em sua própria sala de aula e no modo como procurará vencer suas limitações (linguísticas). Analisemos os relatos abaixo:

[5]

Estudar inglês dentro do CONCOL é uma oportunidade que valorizo muito. Sempre quis fazer curso de inglês para melhorar as minhas aulas. Alguns questionamentos incomodavam-me: se ensino inglês, tenho que saber falar em sala e incentivar os meus alunos a fazer a mesma coisa. Isso era antes muito raro. Falava muito pouco só mesmo as "sentenças" relacionadas para a aula. Não havia comunicação através do inglês. Outro fato, sempre ouvia que lecionar na escola pública (o inglês) era fácil, não 
precisava "saber" era só passar a gramática da língua; só mesmo o básico. Tudo mudou quando ao participar do projeto tive oportunidade de envolver-me mais com o inglês através das aulas que eram aos sábados. Foi então, o começo de um novo pensar sobre minhas aulas. Elas passaram a ser mais significativas. Eu penso que não havia sentido ensinar uma língua a qual eu não falava, não conhecia mais profundamente. (ROSA) (negrito nosso)

[6]

Eu tenho muita dificuldade para falar English na sala de aula e com o auxílio das professoras tenho tentado me esforçar o máximo. $E$ isto tem refletido em minha prática pedagógica porque tenho mais segurança pra transmitir meus conhecimentos aos meus alunos. (MARCELA) (negrito nosso)

[7]

Naturalmente, o aprendizado que acontece no CONCOL levo para sala de aula. Sintome mais motivada a falar em sala e o melhor, PREPARADA para isso. Continuo com muitas dificuldades, mas ao participar do CONCOL surge a necessidade de tomar atividades para melhorar minhas habilidades com a língua. Atitudes como ouvir (texto em meu celular), filmes e falar sempre que possível, com meus alunos em inglês. O CONCOL incentiva-me para aumentar mais e mais esse contato. (ROSA) (negrito nosso. Caixa alta da professora.)

De diferente raiz lexical, mas semanticamente equivalente à palavra enriquecer/ enriquecedor, na fala de Rosa [5] aparece o vocábulo valorizar; dar valor a; reconhecer; bancar/suportar. A professora se posiciona, ante a experiência que ela tenta simbolizar, estabelecendo eventos distintos, sendo, estes, tanto a representação infrutífera do modo como o inglês pode ser tratado em nossas escolas (“não precisava 'saber' era só passar a gramática da língua; só mesmo o básico"), quanto o que ela assumiu viver, a partir de uma nova experiência, pela qual ela se responsabilizou, posicionando-se ("o começo de um novo pensar sobre minhas aulas").

Como vimos acima, os fatos, as atividades e as reflexões decorridas durante o projeto são transportadas para a sala de aula do/a professor/a, que se permite arriscar-se em outra direção, ao transitar entre as posições de aluno e professor. Ao se posicionar, reconhecendo também suas limitações, o/a professor/a ocupa seu lugar (de professor) de modo significativo, abrindo-se aí para a possibilidade de vivenciar deslocamentos subjetivos (REIS, 2016). Deslocamentos subjetivos são compreendidos como formas de reorganização do sujeito nas relações consigo, com seu saber-fazer, com o outro. Deslocamentos exigem, enfim, muito trabalho, muito esforço, muita capacidade de reinvenção (de si) e poucas certezas. Desloca-se, portanto, apenas aquele sujeito que suporta seu agir, responsabilizando-se por ele. 
O uso da expressão 'surge a necessidade', no excerto 7, nos dá pistas desses deslocamentos, que trabalham na constituição subjetiva do/a professor/a, de dentro para fora, estabelecendo novas necessidades, incomodando e levando ao investimento em si, em sua profissão, em sua prática. O professor-sujeito é, portanto, impelido ou motivado ao trabalho. Nos excertos trazidos para esta discussão, atenção deve ser também dada ao uso do verbo tomar, bem como ao uso do verbo no infinitivo, e da primeira pessoa do singular ou plural.

No excerto 8, a seguir, o professor Carlos se inclui no grupo como responsável por uma dada realidade, tomando posição e convocando ao trabalho. Reconhece a existência de um estudo infrutífero, ao mesmo tempo em que, por meio do uso da primeira pessoa do plural, se inclui no grupo daqueles responsáveis por toda e qualquer mudança no ensino da LI em nossas escolas, embora também se afaste, ao fazer referência, em terceira pessoa do singular, ao "profissional [que] precisa se reciclar". Vejamos esses elementos a seguir:

[8]

Enfim, o CONCOL é "materialização" de uma realidade que todos nós somos responsáveis por ela: o profissional precisa se "reciclar" para que a qualidade do estudo de línguas mude em nossas escolas. (CARLOS) (negrito nosso)

[9]

É poder ir além do contexto escolar. É aprender a enriquecer nossas aulas. É poder conhecer outra cultura. É ter a chance de se expressar melhor em inglês porque aprendemos a pronúncia de algumas palavras. A segurança que adquirimos aqui me motiva a ensinar e buscar diferentes caminhos/estratégias para que o aluno compreenda melhor a língua inglesa e para que eu seja uma boa profissional nessa área. (CARLA) (negrito nosso)

Estudar inglês no CONCOL para mim é algo motivador e muito produtivo. Tenho a oportunidade de estar com um 'professor' nativo, tendo assim a oportunidade de praticar o uso real da língua. Tenho também a oportunidade de me manter em constante aperfeiçoamento, e assim, tornar minhas aulas mais interessantes e atraentes para os alunos. (LUCIANA) (negrito nosso)

A oportunidade de estar estudando com nativos da língua, seus accents, feelings e emoções, nos aproximam do idioma, de modo mais prático, porque, podemos fazer perguntas, dentro dos temas que são abordados, ampliando os nossos conhecimentos do idioma inglês. (CARMINHA) (negrito nosso) 
[12]

Está sendo uma boa oportunidade para mim não só aumentando minhas experiências e conhecimentos, mas em todos os sentidos. (ROBERTA) (negrito nosso)

Se, por um lado, o professor projeta para o ConCol a imagem ideal (e, por vezes, equivocada), de que o projeto de EC tem a capacidade de lhe trazer todas as respostas e soluções (“onde as 'falhas', as 'limitações' dos professores são resolvidas de forma realista” [01]); por outro lado, o professor tem em conta aquilo que traz consigo e não pode ser desprezado ou ignorado, e por ele se responsabiliza, como nos apontam os excertos 11 e 12 ("ampliando os nossos conhecimentos do idioma inglês"; "aumentando minhas experiências e conhecimentos").

É importante lançar luz sobre o movimento ativo e aguçado identificado nos dizeres de nossos participantes. Vejamos, nesse sentido, o uso de verbos no infinitivo (poder, aprender, ter, ensinar, buscar, entre outros), que nos indicam um movimento inquieto do professor, frente à complexa experiência de aprender a língua que ele já ensina. Nesse movimento, apontamos que o/a professor/a, nas aulas ofertadas dentro do curso de EC, é impelido a se responsabilizar pela busca de sentido e eficiência para sua trajetória profissional, saindo do isolamento de sua prática ("É poder ir além do contexto escolar") e se descobrindo mais seguro, mais dono, e responsável pela língua que ensina/aprende: "A segurança que adquirimos aqui me motiva a ensinar e buscar diferentes caminhos/estratégias para que o aluno compreenda melhor a língua inglesa e para que eu seja uma boa profissional nessa área" (negrito nosso). Deste modo, a escolha lexical do verbo buscar nos permite vislumbrar esses deslocamentos subjetivos (REIS, 2016), dando indícios do surgimento de fazeres e dizeres, de sujeitos em movimento inquietantemente produtivo, como pode ser apontado no dizer de Luciana, no excerto 10: "Estudar inglês no CONCOL para mim é algo motivador e muito produtivo".

Articulemos, por fim, elementos mobilizados a partir do complexo movimento do/a professor/a entre os lugares/posições de aluno e professor da língua que aprende-ensina, bem como as interpretações do sujeito sobre o curso EC. Vejamos os últimos excertos abaixo:

É saber que não estou só no ensino da língua e esse ganha sentido na minha vida e consequentemente na vida dos meus alunos. De fato aprender inglês dentro do CONCOL me ajuda e muito a desenvolver e ser melhor como professora de inglês. (CARLA) (negrito nosso) 
No CONCOL podemos ainda compartilhar com outros professores, nossas práticas pedagógicas. Cada um tem contribuído para a melhoria da nossa performance profissional, com defesa de pontos de vista, que são vistos como contribuições ao processo de aprendizagem constante do professor. (CARMINHA) (negrito nosso)

Quanto na prática pedagógica, essa troca de experiências e conhecimentos estão sendo enriquecedores. Na vida profissional mais reconhecido ainda, pois a participação de outros profissionais, com os mesmos desafios e reflexões nos conduz para cada vez melhorar mais e mais. (JOELMA) (negrito nosso)

Acredito que o caminho para se tornar um bom professor está na formação continuada. (LUCIANA) (negrito nosso)

Isolado em sua prática cotidiana, o professor é levado a crer, muitas vezes, que está sozinho em seus desafios, reflexões, acertos ou angústias. A EC surge, no entanto, como a outra via, que o informa (faz saber) que ele não está só; que existem formas diferentes de (se) organizar (em) seu fazer e buscar por formas de aprimorar seu saber. A formação continuada pode ser espaço no qual o professor reconheça que seus desafios podem ser compartilhados, e que sua voz pode ser ouvida. É como se, antes, ele não tivesse alcance a essas verdades, ingenuamente tidas como elementares.

A escolha dos verbos saber e compartilhar; ou dos substantivos contribuições e participação, presentes nos excertos 13,14, 15 e 16, é então reveladora da descoberta e da rede de colaboração fomentada nesse ambiente: "É saber que não estou só no ensino da língua [...] e ser melhor como professora de inglês""; "No CONCOL podemos ainda compartilhar com outros professores, nossas práticas pedagógicas"; “[...] defesa de pontos de vista, que são vistos como contribuições ao processo de aprendizagem constante do professor"; “[...] a participação de outros profissionais, com os mesmos desafios e reflexões nos conduz para cada vez melhorar mais e mais".

Como outrora defendido,

Não raras vezes, o professor enfrenta uma solidão em sua prática, enfatizada ou delimitada pela ausência de oportunidades para compreender e trabalhar 
os (in)sucessos e (in)certezas acerca da língua e da metodologia daquilo que ele ensina. (REIS, 2011, p. 505)

Romper essa solidão e isolamento conforta e impulsiona o sujeito a assumir uma posição responsável. Os desafios e acertos ali experimentados fazem ponte com a sala de aula desse professor. Mais que isso, devemos observar o uso do verbo ganhar, pela professora Carla, no excerto 13: "É saber que não estou só no ensino da língua e esse ganha sentido na minha vida e consequentemente na vida dos meus alunos" (negrito nosso). Esse excerto nos permite vislumbrar uma possível angústia vivenciada pelo/a professor/a, quando não consegue ver sentido no ensino da língua. Talvez a própria língua não lhe faça sentido, dadas as suas limitações de trânsito nela. Situação desestabilizada a partir de sua experiência no curso de EC, que, segundo Luciana, no excerto 16, é "o caminho para se tornar um bom professor".

Finalmente, encerramos a seção de análise, indicando que, nos relatos apresentados ao longo deste trabalho, prevalece o tom de movimento, de busca e de descoberta. Vejamos, deste modo, que, no relato 16, Luciana utiliza a palavra caminho, indicando movimento, deslocamento, ação, estrada, responsabilidade.

Reconhecemos, por fim, que não há receita pronta e acabada, em nenhum curso de EC, para as inúmeras demandas vivenciadas pelo professor de LI. Contudo, se não há resposta, podemos dizer que deve haver trabalho responsável, que impele o sujeito a colocar muito de si em cada uma de suas ações, suportando deslocamentos de posição subjetiva. É como se o professor se (re)descobrisse, ao se colocar verdadeiramente em cena, e aí assumir as dores e delícias de tal posição. Responsabilização ganha aqui a conotação de autoria: responsabilizarse é se autorizar a se inscrever no mundo; é presentificar-se em seu fazer; é estar presente. É, enfim, ser, suportando todos os desdobramentos desse ato.

\section{Considerações finais}

Conforme procuramos discutir ao longo deste trabalho, a aula de língua inglesa ocupa o espaço central dentro do projeto de EC para professores dessa língua, pois os convoca ao encontro consigo mesmo, com suas dificuldades, com sua relação com a língua e com o outro à sua volta. A LI muitas vezes parece confrontar tais professores, pois se revela como a língua que ele deve ensinar, sem que, muitas vezes, a conheça de fato. 
Observamos, por fim, a sala de aula, dentro do projeto de EC, como a constituição de um espaço no qual o professor se enxerga a partir da prática e do dizer do outro, estabelecendo uma rede de apoio, em que angústias, desafios, limitações, mas também sucessos são compartilhados e servem de alimento para novas investidas.

Afirmamos, deste modo, que as aulas de LI, dentro do projeto, convocam o/a professor/a a um processo - não sem conflitos ou com certezas - de trabalho, quando, pronto para o embate, se assume com todo seu (não) saber, 'pagando para ver' e suportando deslocarse. Não ousamos afirmar que os professores enfrentam mudanças irreversíveis; mas apostamos nos movimentos que os deslocam para outras posições enunciativas, fazendo que suas antigas representações sejam reorganizadas (NEVES, 2008).

Ao se responsabilizar, no ensino-aprendizagem, o professor abre espaços para (re)significar seu fazer e possíveis limitações, constituindo-se como professor de LI em sua prática e em seu dizer sobre ela. Vemos, enfim, que é necessário assumir(-se), sustentando seu lugar (de professor de LI) e tomando sua posição de modo significativo e responsável. Tratase, enfim, da responsabilização do sujeito diante de si mesmo, diante de suas escolhas e de suas fal(h)as. Responsabilizar-se por ser (professor de LI) é preciso.

\section{Referências bibliográficas}

ALMEIDA FILHO, J.C. O Professor de Língua Estrangeira Sabe a Língua que Ensina? A Questão da Instrumentalização Linguística. In: Contexturas. Ensino Crítico de Língua Inglesa. UNICAMP, 1992.

ARRUDA, C. F. B. É preciso propiciar a aprendizagem de inglês na escola: experiências bem-sucedidas para investir em uma mudança de paradigma. Tese (Doutorado em Estudos Linguísticos) - Programa de Pós-Graduação, Universidade Federal de Minas Gerais, Belo Horizonte, 2014. Disponível em: http://www.bibliotecadigital.ufmg.br/dspace/bitstream/ handle/1843/MGSS-MQPBD/tese_climene_arruda_2014_versao_final_entregue.pdf? sequence $=1$. Acesso em agosto/2017.

BATISTA, M. L. W.; PORTO, M. A. R. Um breve histórico do ensino de línguas estrangeiras no Brasil. In: SANTANA, G. et al. Questões de línguas estrangeiras: línguas estrangeiras em questão. São Cristóvão: Editora UFS; Aracaju: Fundação Oviêdo Teixeira, 2005.

BOHN, H. Os aspectos 'políticos' de uma política de ensino de línguas e literaturas estrangeiras. Linguagem \& Ensino, v. 3, n. 1, p. 117-138. Pelotas: Educat, 2000. Disponível em: http://revistas.ucpel.edu.br/index.php/rle/article/viewFile/286/252. Acesso em agosto/2017. 
COELHO, H. S. H. Experiências, emoções e transformações na educação continuada [manuscrito]: um estudo de caso. Tese (Doutorado em Estudos Linguísticos) - Programa de Pós-Graduação, Universidade Federal de Minas Gerais, Belo Horizonte, 2011. Disponível em: http://www.bibliotecadigital.ufmg.br/dspace/bitstream/handle/1843/DAJR-8H5QQD/ 1318d.pdf? sequence=1. Acesso em agosto/2017.

CORACINI, M. J. F. A celebração do outro. In: CORACINI, M. J. F. Identidade e discurso. Campinas: Argos Ed. Unicamp, 2003, p. 197-221.

COSTA, D. M. Por que ensinar lingua estrangeira na escola de $1^{\circ}$ grau. São Paulo: EPU/EDUC, 1987.

CUNHA, A. G.; MICCOLI L. (Orgs). Faça a diferença: Ensinar línguas estrangeiras na Educação Básica. 1 ed. São Paulo: Parábola Editorial, 2016.

DUTRA, D. P. \& OLIVEIRA, S. B. Prática reflexiva: tensões instrucionais vivenciadas pelo professor de língua inglesa. In: BARCELOS, A.M.F. \& Abraão, M.H.V. (orgs.) Crenças e ensino de línguas: foco no professor, no aluno e na formação de professores. Campinas, SP: Pontes Editores, 2006.

FREEMAN, D. Renaming Experience / Reconstructing practice: Developing New Understanding of Teaching. In: FREEMAN, D. \& RICHARDS, J. Teacher Learning in Language Teaching. Cambridge: Cambridge University Press, 1996.

JONAS, H. [1979] O princípio responsabilidade: ensaio de uma Ética para a civilização tecnológica. Rio de Janeiro: Contraponto/PUC-RIO, 2006.

LEFFA, V. J. Aspectos políticos da formação do professor de línguas estrangeiras. In: LEFFA, V. J. (Org.). O professor de línguas estrangeiras: construindo a profissão. Pelotas: EDUCAT, 2001, v. 1, p. 333-355.

LEFFA, V. J. O ensino de línguas estrangeiras no contexto nacional. Contexturas, APLIESP, n. 4, p. 13-24, 1999. http://www.leffa.pro.br/textos/trabalhos/oensle.pdf. Acesso em novembro/2015.

NEVES, M. S. Identificações subjetivas no discurso sobre avaliação de aprendizagem após um curso de educação continuada. Horizontes, v. 26, n. 2, p. 21-29, jul./dez. 2008

ORLANDI, E. P. Análise de Discurso: princípios e procedimento. Campinas: Pontes, 1999a.

ORLANDI, E. P. Do sujeito na história e no simbólico. Escritos $\mathrm{n}^{0}$ 4. Campinas, SP: publicação do Laboratório de Estudos Urbanos Nudecri/LABERURB, maio, 1999b, p. 17 27.

PAIVA, V. L. M. O. A LDB e a legislação sobre o ensino e a formação de professor de língua inglesa. In: STEVENS, C. M T.; CUNHA, M. J C. (Orgs.). Caminhos e colheitas: ensino e pesquisa na área de inglês no Brasil. Brasília: EdUnb, 2003. 
RAJAGOPALAN, K. A geopolítica da língua inglesa e seus reflexos no Brasil: por uma política prudente e propositiva. In: LACOSTE, Yves; RAJAGOPALAN, K. A geopolitica do inglês. São Paulo: Parábola Editorial, 2005, p. 135-159.

RAJAGOPALAN, K. A identidade lingüística em um mundo globalizado. In: RAJAGOPALAN, K. Por uma lingüística crítica: linguagem, identidade e a questão ética. São Paulo: Parábola Editorial, 2003. p. 57-63.

REIS, V. S. Time, space, and memory in the teaching and learning of English within a Brazilian juvenile detention centre: The effect of suspension in a confused space. In: LAMB, T; MURRAY, G. (Eds). Space, Place and Autonomy in Language Learning. Routledge, 2018.

REIS, V. S. Recusas e deslocamentos subjetivos de duas professoras de inglês em contexto encarcerado. Letras \& Letras, [S.1.], v. 32, n. 3, p. 80-104, nov. 2016. Disponível em: http://www.seer.ufu.br/index.php/letraseletras/article/view/33371. Acesso em janeiro/2018.

REIS, V. S. Identificação e deslocamentos identitários do sujeito aprendiz de uma língua estrangeira. Intersecções - Edição 7, Ano 5, número 1, maio/2012. Disponível em: http://www.portal.anchieta.br/revistas-e-livros/interseccoes/pdf/interseccoes_ano_5_numero _1.pdf. Acesso em janeiro/2018.

REIS, V. S. Identificação e relação entre professor (LE) e formador em um Projeto de Educação Continuada. SIGNUM: Estud. Ling. Londrina, n. 14/1, p. 503-522, jun. 2011. Disponível em: http://www.uel.br/revistas/uel/index.php/signum/article/view/8531. Acesso em janeiro/2018.

REIS, V. S. O diário de aprendizagem de língua estrangeira (Inglês) sob a perspectiva do processo discursivo. 2007. 143 p. Dissertação (Mestrado em Estudos Linguísticos) Universidade Federal de Minas Gerais, Belo Horizonte, 2007. Disponível em http://www.bibliotecadigital.ufmg.br/dspace/bitstream/handle/1843/ALDR-6YPQLP/valdeni reis_diss.pdf?sequence=1. Acesso em janeiro/2018.

REIS, V. S. Representações identitárias em diários de aprendizagem de inglês como LE. In: VI SEMANA DE EVENTOS DA FACULDADE DE LETRAS: ENSINO, PESQUISA E EXTENSÃO. Anais. Belo Horizonte. UFMG, 2006. p. 1-15.

SEIDLHOFER, B. Understanding English as a Lingua Franca. Oxford: Oxford University Press, 2011.

SERRANI-INFANTE, S. M. Resonancias discursivas y cortesía en prácticas de lectoescritura. D.E.L.T.A., v. 17, n. 1, 2001. p. 31-58. Disponível em:

http://www.scielo.br/scielo.php?script=sci_arttext\&pid=S0102-44502001000100002\&lng $=\mathrm{es} \& \mathrm{tlng}=\mathrm{es}$. Acesso em janeiro/2018.

SÓL, V. S. A. Trajetórias de professores de inglês egressos de um projeto de educação continuada: identidades em (des)construção. Belo Horizonte. 259 p. Tese (Doutorado em Linguística Aplicada) - Universidade Federal de Minas Gerais, 2014. Disponível em: http://www.bibliotecadigital.ufmg.br/dspace/bitstream/handle/1843/MGSS-9JEPY5/pdf_tese _final_vanderlice_s_l.pdf?sequence $=1$. Acesso em janeiro/2018. 
ZOLNIER, M. C. A. P. Língua inglesa: expectativas e crenças de alunos e de uma professora do ensino fundamental. Dissertação (Mestrado) - Instituto de Estudos Linguísticos, Universidade Estadual de Campinas. Campinas, SP, 2007. Disponível em: http://repositorio.unicamp.br/bitstream/REPOSIP/269339/1/Zolnier_MariadaConceicaoApare cidaPereira_M.pdf. Acesso em agosto/2017.

\title{
Responsibility for the positioning in the language that I learn/teach: the analysis of the relationships English teachers establish with the (English) classes within a continuing education program
}

\begin{abstract}
This paper aims to investigate the effects of meaning negotiated by English teachers, who take part in a Continuing Education project supported by a federal university in Minas Gerais. It is especially focused on the analysis of discursive/subjective shifts faced by the English teachers as they had the opportunity to attend English classes given by two Americans (Fulbright scholarships) in one of the modules of the project. Mainly based upon responsibility and discursive positioning theories, narratives written by the teachers will be analyzed in order to understand the way they interpret this experience, changing both their practice and the way they position themselves as English teachers. Results indicate that the English classes offered by the Project, invite the teachers to take part in a complex process of taking responsibility for (re)positioning themselves as English teachers.
\end{abstract}

Keywords: Continuing Education for English Teachers. English teachers. Responsibility. Discursive Position. Subjective/discursive shifts

Recebido em 19 de janeiro de 2018.

Aprovado em 22 de maio de 2018. 